\title{
ANALISIS NUMERIK PENGARUH KECEPATAN TERHADAP SEAKEEPING KAPAL PATROLI PADA DAERAH PELAYARAN SEASTATE 7
}

\author{
Mohammad Taufik Ar Rozi ${ }^{1 *}$, Betty Ariani², Dedy Wahyudi ${ }^{3}$ \\ 1Teknik Perkapalan Fakultas Teknik Universitas Muhammadiyah Surabaya, Surabaya 60113 \\ *Email: taufik.umsurabaya@gmail.com \\ 2Teknik Perkapalan Fakultas Teknik Universitas Muhammadiyah Surabaya, Surabaya 60113 \\ Email: betty.ariani@ft.um-surabaya.ac.id \\ ${ }^{3}$ Teknik Perkapalan Fakultas Teknik Universitas Muhammadiyah Surabaya, Surabaya 60113 \\ Email: dewahyudi79@gmail.com
}

\begin{abstract}
Abstrak. Kapal patrol didesain untuk tidak lambat dalam pergerakannya dipermukaan air. Untuk dapat bergerak dengan dengan cepat dan lincah, kebutuhan yang paling penting bagi kapal jenis ini adalah terletak pada olah geraknya. Olah gerak kapal di laut (seakeeping) dipengaruhi oleh beberapa hal diantaranya kecepatan, bentuk badan kapal, dan arah datang kapal terhadap datangnya gelombang. Pada penelitian ini dilakukan analisa terhadap enam derajat kebebasan, khususnya pada respon gerakan kapal secara vertikal yaitu rollingpada gelombang laut seastate 7 khususnya pada cuaca ekstrim di laut Cina Selatan. Standar batasan yang digunakan ialah NORDFORSK 1987 dengan kriteria Light Manual Work. Dengan memasukkan parameter yaitu variasi kecepatan serta sudut gelombang yaitu $0^{\circ}, 45^{\circ}, 180^{\circ}$ dan $270^{\circ}$ akan didapatkan nilai kritis pada setiap gerakan. Perhitungan dilakukan dengan bantuan komputasi software Maxsurf Motions Advanced $20 \mathrm{~V} 8 \mathrm{i}$, Hasil penelitian menunjukkan bahwa nilai gerakan roll maksimum terjadi pada saat kecepatan 14 knots, kondisi sudut datang gelombang $45^{\circ}$ dengan nilai sudut roll sebesar $6.40^{\circ}$. Selanjutnya terjadi penurunan nilai gerakan roll seiring dengan bertambahnya kecepatan kapal. Nilai roll minimum terjadi sudut datang gelombang $270^{\circ}$ saat kecepatan kapal 28 knots dengan nilai 5.69 .
\end{abstract}

Kata kunci: Seakeeping, Sudut Roll, Wave heading, kapal patroli, kecepatan kapal

\begin{abstract}
Patrol boat is designed not to be slow in its movement on the water surface. To be able to move quickly and agilely, the most important requirement for this type of ship is in its maneuverability. The ship's motion at sea (seakeeping) is influenced by several things, speed, body shape, and the direction of the ship's heading waves. In this study, we analyze the six degrees of freedom, especially on the response of the ship's vertical movement, namely rolling on the sea waves of Seastate 7, especially in extreme weather in the South China Sea. The standard limit used is NORDFORSK 1987 with Light Manual Work Criteria. By entering parameters such as variations in speed and wave angle, such as $0^{\circ}, 45^{\circ}, 180^{\circ}$ and $270^{\circ}$, then from the graph it can be seen the critical value for each movement. The calculation is carried out with the help of computational software Maxsurf Motions Advanced 20 V8i. The results of this study are the maximum roll movement value that occurs at a speed of 14 knots with a wave angle of $45^{\circ}$ with a roll angle value of $6.40^{\circ}$. Furthermore, there is a decrease in the value of the movement along with the increase in the speed of the ship. The minimum roll value occurs when the wave angle is $270^{\circ}$ when the ship's speed is 28 knots with a value of $5.69^{\circ}$.
\end{abstract}

Keywords: Seakeeping, Roll angle, Wave heading, fast patrol boat, ship speed

\section{PENDAHULUAN}

Kapal dalam operasinya sangat dipengaruhi oleh kondisi laut terutama besar kecilnya gelombang. Salah satu contohnya adalah Kapal Cepat Rudal. Gerakan kapal akibat gelombang sangat perlu diperhitungkan dalam tahap awal 
desain. Kapal ini didesain untuk tidak lambat dalam pergerakannya dipermukaan air. Untuk dapat bergerak dengan dengan cepat dan lincah, kebutuhan yang paling penting bagi kapal jenis ini adalah terletak pada olah geraknya.

Kapal patroli merupakan salah satu armada laut yang menjadi bagian dari struktur kekuatan yang dibutuhkan negara dalam menghadapi ancaman kedaulatan dan keutuhan sebuah negara. Kriteria khusus yang harus dimiliki oleh sebuah kapal cepat patroli adalah kemampuan bermanuver dipermukaan air, kemampuan untuk mengejar musuh dan menyerang tanpa bisa terdeteksi terlebih dahulu.

Gelombang merupakan faktor yang penting dalam pelayanan informasi meteorologi kelautan (marine meteorological services). Sering terjadinya gelombang tinggi tentu dapat menyebabkan terganggunya aktivitas dilaut seperti nelayan, transportasi laut antar pulau yang dapat berdampak pada kehidupan masyarakat di darat, seperti kelangkaan bahan pangan di beberapa pulau kecil dan terganggunya berbagai aktifitas pembangunan karena terhambatnya suplai bahan-bahan konstruksi (Marelsa, 2019). Pada umumnya gelombang laut dibangkitkan oleh angin (sea wave) sehingga sifat-sifat gelombang tertentu dipengaruhi oleh angin, misalnya semakin kencang atau tinggi kecepatan angin maka kecepatan dan panjang gelombang semakin besar. Menurut BMKG, ada beberapa kriteria tingkat bahaya gelombang laut yaitu 1,25 - 2 meter berbahaya bagi perahu nelayan, $2-3$ meter berbahaya bagi perahu nelayan dan tongkang, 3 4 meter berbahaya bagi perahu nelayan, tongkang dan kapal feri, diatas 4 meter berbahaya bagi semua kapal.

Pengaruh Samudera Pasifik menjadi dominan pada periode angin baratan kecuali pada sebagian besar Sumatera, yang dipengaruhi oleh karakteristik Samudera Hindia sebelah barat. Sebaliknya pada musim angin timuran, pengaruh Samudera Hindia menjadi dominan dengan ditandai oleh berkurangnya curah hujan di Pulau Jawa, dan kepulauan Nusa Tenggara, sementara di sebagian besar Sumatera, dan Kalimantan masih berpeluang terjadinya curah hujan dengan intensitas sedang. Dinamika ini akan berpengaruh secara langsung terhadap dinamika yang terjadi di perairan Indonesia.

Wilayah perairan Utara Equator dalam penelitian ini meliputi 6 (enam) wilayah diantaranya adalah perairan Laut Cina Selatan, Samudera Pasific, Perairan Barat Sumatera Utara, perairan Utara Papua, Laut Sulawesi, dan Laut Maluku. Di daerah belahan Utara Equator, ketinggian gelombang ekstrim (H.eks) di atas 4.73 $\mathrm{m}$ dimana merupakan batas tertinggi gelombang yang tidak bisa dilalui kapal patroli terjadi di perairan Laut Cina Selatan dengan ketinggian gelombang eksrim mencapai 6,1 hingga $7.2 \mathrm{~m}$, diperairan Samudera Pasific dengan ketinggian antara 4.8 hingga $5.2 \mathrm{~m}$ di musim moonsun Asia dan Australia serta perairan Barat Sumatra Utara dengan ketinggian $4.8 \mathrm{~m}$ di bulan Agustus. Sedangkan diwilayah Utara Papua, Laut Sulawesi dan Laut Maluku rata-rata tinggi gelombang ekstrim dibawah $4.73 \mathrm{~m}$ baik dimusim moonsun Asia, moonsun Australia maupun ke dua moonsun peralihan yaitu periode antara moonsun Asia dan moonsun Australia yaitu bulan Maret, April dan Mei serta periode antara moonsun Australia dan moonsun Asia yaitu bulan September, Oktober dan Nopember

Terdapat kriteria seakeeping oleh NORDFORSK 1987 berupa percepatan vertikal, percepatan lateral, dan gerakan rolling yang dialami oleh kapal jenis tertentu yang ditujukkkan Tabel 1.

Tabel 1. Kriteria untuk percepatan dan roll NORDFORSK 1987

\begin{tabular}{ccccc} 
No. Deskripsi & $\begin{array}{c}\text { RMS } \\
\text { percepatan } \\
\text { vertikal }\end{array}$ & $\begin{array}{c}\text { RMS } \\
\text { percepatan } \\
\text { lateral }\end{array}$ & $\begin{array}{c}\text { RMS } \\
\text { Sudut } \\
\text { roll }\end{array}$ \\
\hline $1 \quad \begin{array}{l}\text { Light } \\
\text { manual work }\end{array}$ & $0.20 \mathrm{~g}$ & $0.10 \mathrm{~g}$ & $6^{\circ}$ \\
$2 \begin{array}{l}\text { Heavy } \\
\text { manual work }\end{array}$ & $0.15 \mathrm{~g}$ & $0.07 \mathrm{~g}$ & $4^{\circ}$ \\
$3 \begin{array}{l}\text { Intellectual } \\
\text { work } \\
4\end{array}$ & $0.10 \mathrm{~g}$ & $0.05 \mathrm{~g}$ & $3^{\circ}$ \\
& $\begin{array}{l}\text { Transit } \\
\text { passengers }\end{array}$ & $0.05 \mathrm{~g}$ & $0.04 \mathrm{~g}$ & $2^{\circ} .^{\circ}$ \\
5 & $0.02 \mathrm{~g}$ & $0.03 \mathrm{~g}$ & $2^{\circ}$ \\
\hline
\end{tabular}

Perhitungan stabilitas kapal menggunakan prinsip kesetimbangan gaya dan momen. Ketika kapal mengapung di atas permukaan air, bekerja dua jenis gaya yang sama besar yaitu: gaya berat (G) yang arahnya ke bawah dan gaya apung (B) yang arahnya ke atas. Ketika kapal berlayar, kapal akan menerima gaya dari luar berupa angin dan gelombang, yang akan membuat kapal oleng (Gambar 1).

Gaya B dan $G$ mula-mula terletak pada satu garis lurus di centerline, namun saat mendapat gaya dari luar kapal akan miring. Posisi tersebut membuat gaya $\mathrm{B}$ akan berpindah menyesuaikan bentuk badan kapal yang masuk ke dalam air, sedangkan gaya $\mathrm{G}$ posisinya tetap tetapi arahnya 
tidak lagi segaris dengan centerline. Saat gaya luar hilang, gaya berat dan gaya apung akan membentuk momen kopel dan lengan momen kopel kedua gaya tersebut disebut GZ seperti pada Gambar 1. Jika lengan GZ ini positif kapal akan mampu kembali ke posisi semula (stabil) dan jika GZ negatif maka kapal akan terbalik (labil) setelah gaya dari luar hilang.

Nilai GZ positif belum tentu menjamin kapal tidak akan terbalik. International Maritime Organization (IMO) telah menetapkan kriteria stabilitas kapal dalam peraturan A.749 Code on Intact Stability 2008 (IS 2008).

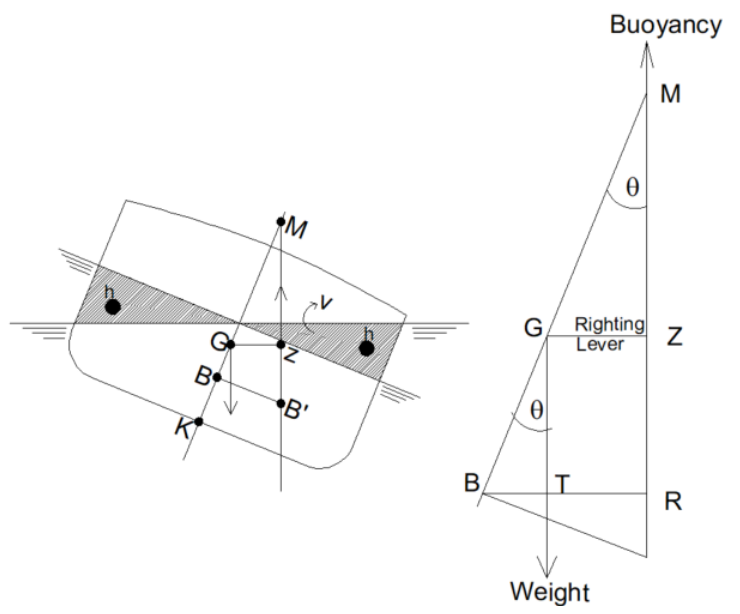

Gambar 1. Lengan stabilitas

Penelitian dilakukan melalui metode simulasi seakeeping menggunakan software maxsurf motion dan perhitungan manual lainnya. Standar yang digunakan untuk kriteria penilaian seakeeping kapal patroli yaitu NORDFOSK 1987.

\section{BAHAN DAN METODE}

Penelitian dilaksanakan di salah satu galangan kapal yang terletak di Tanjung Perak Surabaya, Provinsi Jawa Timur. Tahapan pertama dalam penelitian adalah mengumpulkan data berupa gambar sketsa dan ukuran kapal, yang meliputi dimensi utama kapal dan koordinat lambung kapal dan bobot kapal.Tahapan selanjutnya adalah pemodelan lambung kapal dengan bantuan software Maxsurf Motions Advanced 20 V8i. Pada tahapan ini, hasil sketsa dan pengukuran koordinat kapal di lapangan, direkonstruksi ulang untuk mendapatkan model lambung yang menyerupai bentukkapal aslinya. Hasil pemodelan divalidasi dengan hasil perkiraan berat kapal kosong.

Hasil pengukuran kapal langsung di lapangan didapatkan bahwa ukuran utama kapal yaitu, panjang kapal total adalah 59.8 meter, lebar 8.1 meter, dalam 4.85 meter, dan sarat 2.6 meter.
Tabel 2. Parameter yang diinputkan untuk simulasi kapal patroli

\begin{tabular}{|c|c|c|}
\hline No. & Input Data & $\begin{array}{c}\text { Parameter komputasi } \\
\text { hidrostatik }\end{array}$ \\
\hline 1 & Draft maksimum & $2.6 \mathrm{~m}$ \\
\hline 2 & Jumlah section & 41 \\
\hline 3 & Tipe kapal & Monohull \\
\hline \multirow[t]{3}{*}{4} & Spectra & JONSWAP \\
\hline & a. Characteristic height & $7.2 \mathrm{~m}$ \\
\hline & b. Modal periode & $9.977 \mathrm{~s}$ \\
\hline \multirow{4}{*}{$\begin{array}{l}5 \\
6 \\
7\end{array}$} & Sudut datang gelombang & $0^{\circ}, 45^{\circ}, 180^{\circ}, 270^{\circ}$ \\
\hline & Kecepatan maksimum & $28 \mathrm{knot}$ \\
\hline & Vertical Centre of & \\
\hline & Gravity & $2.612 \mathrm{~m}$ \\
\hline
\end{tabular}

Gambar 2. Pemodelan lambung kapal dengan menggunakan software Maxsurf Motions

\section{HASIL DAN PEMBAHASAN}

Analisa olah gerak kapal (seakeeping) ini bertujuan untuk menentukan kondisi kritis kapal dan dilakukan dengan memvariasikan beberapa komponen yang berpengaruh dalam menentukan besarnya amplitudo simpangan lateral acceleration, vertical acceleration dan roll. Pada analisa olah gerak kapal ini dilakukan dengan memvariasikan kecepatan kapal yaitu pada kecepatan 14 knots, 16 knots dan full speed 28 knots.

Pada kondisi kecepatan kapal 14 knot, respon gerakan roll kapal paling besar terjadi ketika wave heading 45 derajat (Quartering beam seas), sudut roll yang terjadi mencapai 6.40 derajat. Sedangkan respon gerakan roll kapal paling kecil terjadi ketika wave heading 270 derajat (Port beam seas), sudut roll yang terjadi mencapai 5.70 derajat. Kapal mengalami respon signifikan gerakan rollyang cukup besar yaitu hingga melebihi 6 derajat pada kondisi VCG 2,6 mdengan kecepatan kapal sebesar 14 knots. Dan untuk nilai RMS vertical acceleration dan RMS lateral acceleration masih di bawah standar.

Pada kondisi kecepatan kapal 16 knot, respon gerakan roll kapal paling besar terjadi ketika wave heading 45 derajat (Quartering beam seas), sudut roll yang terjadi mencapai 6.16 derajat. Sedangkan respon gerakan roll kapal paling kecil terjadi ketika wave heading 270 derajat (Port 
beam seas), sudut roll yang terjadi mencapai 5.70 derajat.

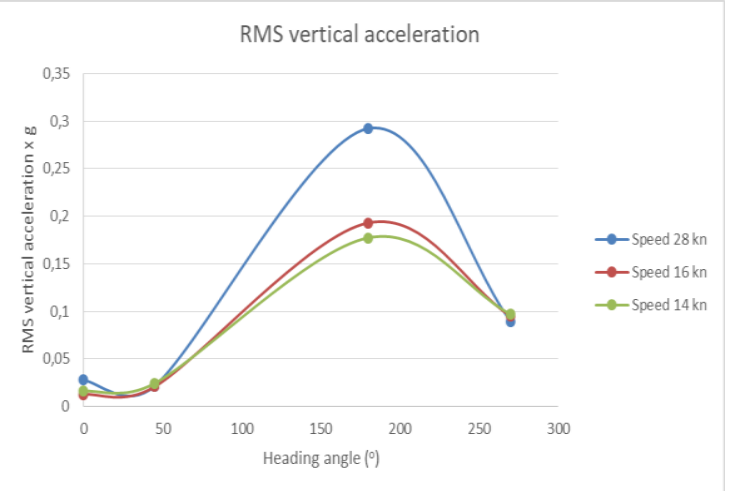

Gambar 3. Variasi kecepatan terhadap RMS vertical accelerations

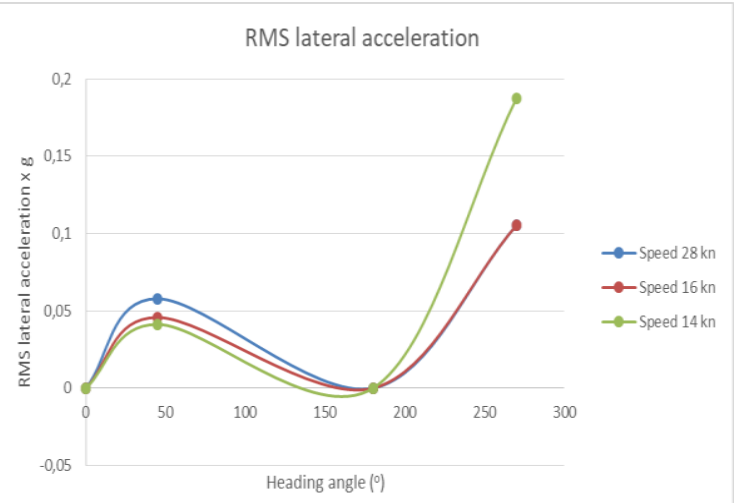

Gambar 4. Variasi kecepatan terhadap RMS lateral accelerations

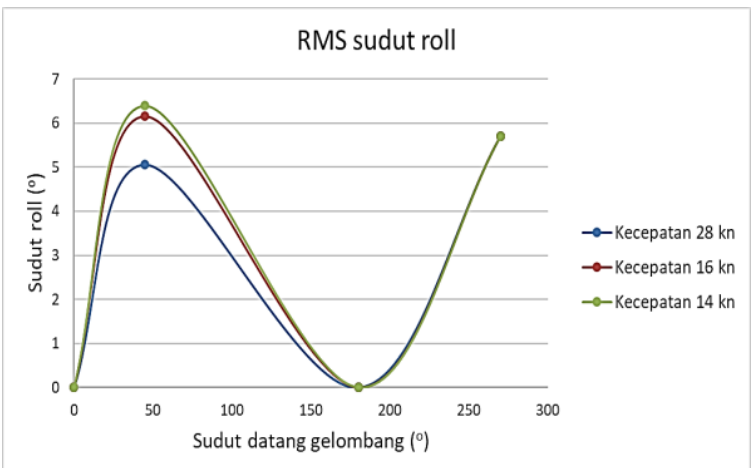

Gambar 5. Grafik hubungan antara sudut roll dengan sudut datang gelombang pada beberapa variasi kecepatan

Pada kondisi kecepatan kapal 28 knot, respon gerakan roll kapal paling kecil terjadi ketika wave heading 45 derajat (Quartering beam seas), sudut roll yang terjadi mencapai 5,07 derajat. Sedangkan respon gerakan roll kapal paling besar terjadi ketika wave heading 270 derajat (Port beam seas), sudut roll yang terjadi mencapai 5,69 derajat

Perlu digaris bawahi kembali di sini bahwa frekuensi gelombang adalah merupakan salah satu faktor penting yang mempengaruhi perilaku bangunan laut, karena dari adanya frekuensi pada nilai tertentu akan menimbulkan kondisi resonansi atau magnifikasi respons. Secara teoritis semakin tinggi gelombang laut maka nilai frekuensinya akan semakin rendah. Bila titik tinjau gelombang, atau bangunan laut yang dikaji, tidak lagi stasioner tetapi bergerak melaju dengan kecepatan tertentu maka efek frekuensi gelombang yang diterima pada bangunan laut akan berubah. Perubahan frekuensi ini tidak lain adalah karena adanya kecepatan relatif antara gelombang dan bangunan laut yang melaju. Sebagai akibatnya perubahan tersebut tentunya akan merubah hasilhasil perhitungan perameter-parameter ataupun koefisien-koefisien hidrodinamika, yang akhirnya memberikan hasil akhir berupa respons yang berbeda pula. Frekuensi yang berubah karena gelombang berpapasan dengan bangunan laut yang melaju disebut sebagai frekuensi gelombang papasan atau encountering wave frequency, sering disingkat sebagai frekuensi papasan atau encountering frequency, yang diberi notasiwe.

$$
\omega e=\omega\left[1-\frac{\omega V s}{g} \cos \mu\right]
$$

Dimana:

$\omega \mathrm{e}=$ Frekuensi papasan

$\omega=$ Frekuensi riil gelombang

Vs = Kecepatan Struktur

$\mu=$ Sudut hadap

Respon gerakan kapal terhadap gelombang regular dinyatakan dalam RAO (Response Amplitudo Operator), dimana RAO adalah rasio antara amplitudo gerakan kapal (baik translasi maupun rotasi) terhadap amplitudo gelombang pada frekuensi tertentu. RAO memuat informasi tentang karakteristik gerakan bangunan laut yang disajikan dalam bentuk grafik, dimana absisnya adalah parameter frekuensi, sedangkan ordinatnya adalah rasio antara amplitudo gerakan pada mode tertentu, $\zeta 0$, dengan amplitudo gelombang, $\zeta 0$

$$
R A O=\frac{a_{0}}{\omega_{e}^{2} \zeta_{0}}
$$

Karakteristik gerak roll kapal patroli pada gelombang di seastate 7 dipengaruhi oleh kecepatan, arah gelombang. Hasil analisis RAO model kapal adalah sebagai berikut

Dari ketiga variasi tersebut, sudut roll paling kecil ialah pada saat kapal melaju pada kecepatan maksimum (28 knots). Kecepatan kapal berbanding lurus dengan frekuensi encountering 
atau frekuensi papasan antara gelombang dengan laju kapal. Sedangkan frekuensi encountering berbanding terbalik dengan RAO sehingga menyebabkan nilai RAO semakin rendah dan terjadi penurunan sudut roll seiring dengan penambahan kecepatan kapal.

Menurut analisa bahwa sudut rollakan maksimal pada sudut datang gelombang $90^{\circ}$ atau $270^{\circ}$. dan akan minimum pada saat arah datang gelombang searah dengan arah laju kapal karena pada kenyataannya pada saat pelayaran kapal selalu bergerak memotong gelombang tertinggi jadi sangat kecil kemungkinannya kapal terdorong oleh gelombang tertinggi pada bagian samping kapal atau pada sudut datang $90^{\circ}$.

$$
R A O_{\text {Roll }}(\mu)=R_{\text {Roll }} \sin (\mu)
$$

Berdasarkan hasil simulasi ditemukan fakta bahwa ketika kapal melaju dibawah kecepatan 20 knots pada tinggi gelombang 7,2m, kapal akan mengalami sudut roll sebesar $\pm 7,5^{\circ}$ dengan kondisi pelayaran dengan cuaca ekstrim. Kondisi ini sangat membahayakan jika kapal digunakan untuk berlayar.

\section{KESIMPULAN}

Berdasarkan hasil analisis, diketahui bahwa: Pada kecepatan kapal 14 dan 16 knots, sudut roll kapal tidak memenuhi kriteria NORDFORSK 1987 untuk Light Manual Work.

Karakteristik gerak model kapalpada gelombang laut seastate 7 dipengaruhi oleh kecepatan, arah gelombang.Hasil simulasi model kapal cepat patroli adalah nilai gerakan roll maksimum terjadi pada saat kecepatan 14 knots kondisi sudut datang gelombang $45^{\circ}$ dengan nilai sudut roll sebesar6.40 ${ }^{\circ}$. Selanjutnya terjadi penurunan nilai gerakan roll seiring dengan bertambahnya kecepatan kapal. Nilai roll minimum terjadi sudut datang gelombang $270^{\circ}$ saat kecepatan kapal 28 knots dengan nilai 5.69 .

Penambahan kecepatan kapal secara umum dapat meningkatkan kualitas stabilitas kapal pada daerah dengan gelombang tinggi, sehingga dapat dikatakan bahwa semakin cepat suatu kapal maka gerakan roll-nya akan lebih stabil.

\section{DAFTAR PUSTAKA}

[1] Marelsa, Nadia Friska dan Yosyea Oktaviandra. Analisis Karakteristik Gelombang Laut Menggunakan Software Windwave-12 (Studi Kasus: Kepulauan Mentawai). Oseana, 10 - 24, 2019
[2] Hasanudin, Y. Totok, dan A. Rizky Chandra, Modifikasi Kapal Purse Seine 30 GT Dengan Menambahkan Cadik Untuk Meningkatkan Survival of Intact Stability, Marine Fisheries, 205-213, 2019.

[3] IMO. 1990. Intact Stability Code. Assembly Res. A. 749. London: International Maritime Organization.

[4] Prasetyo, Bonaventura Danis., Suastika, Ketut. Kajian Eksperimental dan Numeris Olah Gerak (Seakeeping) Kapal Crew Boat Orela Dengan dan Tanpa Foil Belakang, JURNAL TEKNIK ITS, 2301-9271, 2016.

[5] Hutauruk, Ronald Mangasi dan Rengi, Pareng. Respons Gerakan Kapal Perikanan Hasil Optimisasi Terhadap Gelombang. Jurnal Perikanan Dan Kelautan. 2014

[6] Hardjono, Soegeng. Analisa Ketinggian Gelombang yang Sesuai untuk Pengoperasian Kapal Cepat Rudal 60m di Perairan Indonesia. 2018.

[7] Muh AA, Iskandar BH, Novita Y. 2017. Kajian Desain Kapal Purse Seine Tradisional di Kabupaten Pinang (Studi Kasus KM Cahaya Arafah). ALBACORE. 1(1): 69-76.

[8] Romadhoni. Analisa Seakeeping Ferformance Kapal Cepat Model Planing Hull Chine. JURNAL INOVTEK POLBENG. 2019

[9] Brillin, Dimas Berifka, Agoes Santoso, dan Irfan Syarif Arief. Analisa Seakeeping pada Offshore SupplyVessel 56 Meter. 23019271.2015.

[10] Bhattacharyya. (1978). Dynamic of marine Vehicles. United State of America.

[11] Putra, Dian Purnama, Deddy Chrismianto, dan Muhammad Iqbal. Analisa Seakeeping Dan Prediksi Motion Sickness Incidence ( MSI ) Pada Kapal Perintis 500 Dwt Dalam Tahap Desain Awal ( Initial Design ). Jurnal Teknik Perkapalan UNDIP. 562-575. 2016.

[12] Hayatul Fajar, Azhabul, Deddy Chrismianto, dan Eko Sasmito Hadi. Studi Analisa Slamming \& Deck Wetness Akibat Gerakan Heaving - Pitching Coupling \& Gerakan Non-Linier Rolling (Studi Kasus Kapal MT. Pandan). 677-687. 2017. 